\title{
Psychological effects of the pandemic on caregivers of older adults: A rapid
}

\section{systematic review}

\author{
Efeitos psicológicos da pandemia em cuidadores de idosos: Revisão sistemática rápida \\ Efectos psicológicos de la pandemia en los cuidadores de ancianos: Revisión sistemática rápida
}

Received: 06/13/2021 | Reviewed: 06/19/2021 | Accept: 06/22/2021 | Published: 07/08/2021

\author{
Willian Roger Dullius \\ ORCID: https://orcid.org/0000-0003-3144-378X \\ University of Passo Fundo, Brazil \\ E-mail: rogerdullius@gmail.com \\ Álisson Secchi \\ ORCID: https://orcid.org/0000-0003-0002-3192 \\ University of Passo Fundo, Brazil \\ E-mail: alissonsecchi@gmail.com \\ Silvana Alba Scortegagna \\ ORCID: https://orcid.org/0000-0002-5100-6459 \\ University of Passo Fundo, Brazil \\ E-mail: silvanalba@upf.br
}

\begin{abstract}
The COVID-19 pandemic has rendered numerous impacts on society, especially to caregivers of older adults, who are facing many tasks. These elevated number of demands and modifications can affect these caregivers' mental health. This study aimed to gather empirical evidence on existing researches about the impact of caregiver's mental health of older adults during the COVID-19 pandemic. This rapid systematic review, developed from international and Brazilian databases from January/2020 to April/2021, identified 4714 potentially relevant articles, published in English and Portuguese. Eighteen (18) articles that potentially met the inclusion criteria were screened and read. Eleven of them met the inclusion criteria and were selected for this review. Caregivers of older adults demonstrate different psychological manifestations such as higher levels of stress, anxiety, sleep problems, depression, somatic symptoms, and poor quality of life. Those can directly influence the care provided to the older adults. Knowing the effects on the caregivers can be conducted psychological interventions to prevent and minimize impacts in their lives.

Keywords: Caregivers; Coronavirus infections; Pandemic; Psychological distress; Older adult.
\end{abstract}

\section{Resumo}

A pandemia COVID-19 causou inúmeros impactos na sociedade, especialmente para cuidadores de idosos, que enfrentam muitas tarefas. Este elevado número de demandas e modificações podem afetar a saúde mental desses cuidadores. Este estudo teve como objetivo reunir evidências empíricas sobre as pesquisas existentes sobre o impacto da saúde mental do cuidador de idosos durante a pandemia COVID-19. Está rápida revisão sistemática, desenvolvida a partir de bases de dados internacionais e brasileiras de janeiro/2020 a abril/2021, identificou 4.714 artigos potencialmente relevantes, publicados em inglês e português. Dezoito (18) artigos que potencialmente atenderam aos critérios de inclusão foram selecionados e lidos. Onze deles atenderam aos critérios de inclusão e foram selecionados para esta revisão. Cuidadores de idosos demonstram diferentes manifestações psicológicas, como níveis mais elevados de estresse, ansiedade, problemas de sono, depressão, sintomas somáticos e baixa qualidade de vida. Esses podem influenciar diretamente no cuidado prestado aos idosos. Conhecendo os efeitos sobre os cuidadores, podem ser realizadas intervenções psicológicas para prevenir e minimizar impactos em suas vidas.

Palavras-chave: Cuidadores; Infecção por Coronavírus; Pandemia; Angústia psicológica; Idoso.

\section{Resumen}

La pandemia de COVID-19 ha tenido numerosos impactos en la sociedad, especialmente para los cuidadores de ancianos, quienes enfrentan muchas tareas. Este elevado número de demandas y modificaciones puede afectar la salud mental de estos cuidadores. Este estudio tuvo como objetivo recopilar evidencia empírica sobre la investigación existente sobre el impacto de la salud mental de los cuidadores de ancianos durante la pandemia de COVID-19. Esta rápida revisión sistemática, desarrollada a partir de bases de datos internacionales y brasileñas desde enero de 2020 hasta abril de 2021, identificó 4.714 artículos potencialmente relevantes, publicados en inglés y portugués. Se seleccionaron y leyeron dieciocho (18) artículos que potencialmente cumplían con los criterios de inclusión. Once de ellos cumplieron con los criterios de inclusión y fueron seleccionados para esta revisión. Los cuidadores de ancianos presentan diferentes manifestaciones psicológicas, como niveles más altos de estrés, ansiedad, problemas de sueño, depresión, síntomas somáticos y mala calidad de vida. Estos pueden influir directamente en la atención que se brinda 
a las personas mayores. Conociendo los efectos sobre los cuidadores, se pueden realizar intervenciones psicológicas para prevenir y minimizar los impactos en sus vidas.

Palabras clave: Cuidadores; Infecciones por coronavirus; Pandemia; Trastorno sicológico; Adulto mayor.

\section{Introduction}

The population's mental health aggravates during a serious social crisis. The COVID-19 pandemic can be described as one of those crises, and it has been one of the biggest public health problems of the last decades, having reached essentially the entire planet. An event like this causes psychological and social disturbances that affect the coping capacity of the whole society, at varying levels of intensity (World Health Organization, 2020), a collective trauma, an epidemiological and psychological crisis (American Psychological Association, 2020).

Social confinement implies high levels of stress and can compromise people's mental health, which associated with sleep disorders, anxiety, fear, irritability, changes in appetite, consumption of alcohol, and other drugs, can impact in the mental health, especially in more vulnerable individuals (Brooks et al., 2020; Moraes, 2020). Recently, different national and international organizations have expressed their views on the psychological effects of the pandemic and the importance of mental health care (World Health Organization, 2020).

The impact of the COVID-19 pandemic on mental health is highlighted by health professionals around the world, indicating the increase in symptoms of irritability, sadness, depression, with an increase in cases of domestic violence, that can be aggravated with sickness and from the country's economic and social uncertainties, in this new context (Nasem, 2020, Vaitheswaran et al., 2020). The COVID-19 pandemic created a word scenario with impacts on the mental health of the populations and with more intensity in populations with vulnerability. Thus, caregiving activities may be more struggling due to lockdowns imposed by the government, social distancing, difficulties in fulfilling the basic needs of the older adult, and accessing the health system during the pandemic. Providing care for older adults is a stressful experience that may have a negative impact on psychological well-being (Pinquart \& Sörensen, 2003; Sallim, Sayampanathan, Cuttilan, \& Ho, 2015), and for example, for caregivers of people with dementia, this process of social isolation can increase their levels of depression rather other psychological symptoms (Altieri \& Santangelo, 2021).

Hence, in a pandemic characterized by extreme uncertainty, the lockdown may likely have exacerbated psychological reactions such as anxiety and depression in caregivers (Sallim et al., 2015). Family caregivers are largely responsible for the care of the next of kin living at home, which impacts their own physical and mental health with both positive and negative aspects (Fagerström, Elmståhl, \& Wranker, 2020). However, the social distancing required in the COVID-19 pandemic can compromise the quality of life and health of older adults and their caregivers; this isolation process emphasizes this effects on vulnerable groups (Lai et al., 2020).

A family caregivers are defined as a relatives, partners, friends, or neighbors providing a broad range of assistance for a care recipient and may be primary or secondary caregivers and live with or independently from the recipient (Family Caregiver Alliance National Center on Caregiving, 2014). The conceptual framework Informal Caregiving Integrative Model (ICIM) can highlight the caregiver psychological effects in this pandemic moment. The ICIM framework describe the informal caregiver burnout in the respective categories as a relating the caregiving, the caregiving setting, and the sociocultural context; these categories made a role for the caregivers' appraisal of their situation and their relationship the care-recipient (Gérain \& Zech, 2019).

In situations of extreme collective vulnerability, such as the produced by the pandemic of COVID-19, caring for the other and the preservation of mental health is fundamental because community traumatisms produce resonances and have an impact on psychological and social life (World Health Organization, 2020). Given the importance of understanding the mental 
health impacts of caregiver of older adult from the COVID-19, this study inquired "What are the mental health impacts of caregiver of older adult in front of the COVID-19 pandemic?". To answer this question, this rapid systematic review aimed to gather empirical evidence on existing researches about the mental health impact of caregiver of older adult during the COVID19 pandemic.

\section{Methodology}

This is a rapid systematic review in response to the COVID-19 pandemic. A rapid review follow the general guidelines for traditional systematic review, but it is simplified to produce evidence rapidly. When evidence synthesis is urgently needed, rapid reviews are recommended to inform public health guidelines and policies (World Health Organization, 2017). Following this perspective, this rapid systematic review was conducted according to the recommendation proposed by the PRISMA guideline - Preferred Reporting Items for Systematic Reviews and Meta-Analyses (Moher, Liberati, Tetzlaff, \& Altman, 2009).

The material selected for this study consisted of empirical articles, with qualitative, quantitative, or mixed designs, about the mental health impact of caregiver of older adult from the COVID-19 pandemic. The eligibility criteria were: articles published in January/2020 to April/2021, in peer-reviewed, index journals, available in full text, with open access, in Portuguese or in English. Studies were included if they reported the mental health impact of caregiver of older adult in the context of the COVID-19, and caregiver as a family/informal caregiver with age above 18 years old. Thus, articles that referred to the general effects of the pandemic or health professionals as caregivers were excluded, as well as publications that did not report research findings (e.g., comments, editorials, literature reviews, grey literature).

Initially, searches were performed in the Medical Subject Heading of US National Library of Medicine (NLM $\mathrm{MeSH}$ ) and Health Sciences Descriptors (DeCS) to identify the descriptors, and using the PICO strategy (population, intervention, outcomes) which were defined together with the Boolean operators. A Boolean strategy was employed, using the descriptors ("carers" OR "caregivers" OR "family caregiver" OR "spouse caregiver") AND "COVID-19") with the respective corresponding Portuguese terms. We used quotation marks in each keyword to narrow the results to our topic of interest. The choice of the keywords aimed to discover the largest number of articles involving indicators of caregivers of older adult.

The search for the articles covered sixteen months, from January 2020 to April 2021, thus including publications from the start of the pandemic. The databases searched for this review were PsycINFO, PubMed Central: PMC, Scielo (Scientific Electronic Library online), and ScienceDirect. These databases are relevant to the review question, as they cover journals that would publish the research targeted by this review, including publications across disciplines and professions, and Brazilian and international publications.

The process to select the studies happened simultaneously and independently by the researchers, in the following stages: stage 1 - identification of studies in the databases by the descriptors in DeCs/MeSH; stage 2 - searching for articles: title and abstracts were analyzed to determine if the study addressed the topic of interest; stage 3 - eligibility: the studies were evaluated by reading in full to determine their suitability to the topic, and the eligibility criteria were considered, culminating in the inclusion of the studies. Evaluations with similar results were maintained, but when there were evaluations with divergent results a third person was consulted to evaluate the studies.

\section{Results and Discussion}

The search identified 4714 possible publications: in PsycINFO ( $n=241)$, PubMed Central: PMC ( $n=846)$, SciELO $(n=0)$, and ScienceDirect $(n=3627)$. The titles and the abstracts of these publications were read to check whether they answered 
the research question applied.

Next, 4696 publications did not meet the inclusion criteria and were excluded. The remaining articles $(n=18)$ were then read in full. Of these, 07 articles were excluded, considering the inclusion and exclusion criteria, for the following reason: studies did not focus on the caregivers' mental health effects of older adult from the COVID-19 pandemic, caregivers as a health professional (nurses), or the research data was collected before the COVID-19 pandemic. Accordingly, eleven articles were elected to compose the qualitative analysis, which aimed to summarize and describe existing research about the mental health impact of caregiver of older adults related to the COVID-19 pandemic. Figure 1 shows the flowchart of the article search strategy used in this systematic review and the results achieved.

Figure 1. Flowchart of the article search strategy in the databases and results found.

.0ี
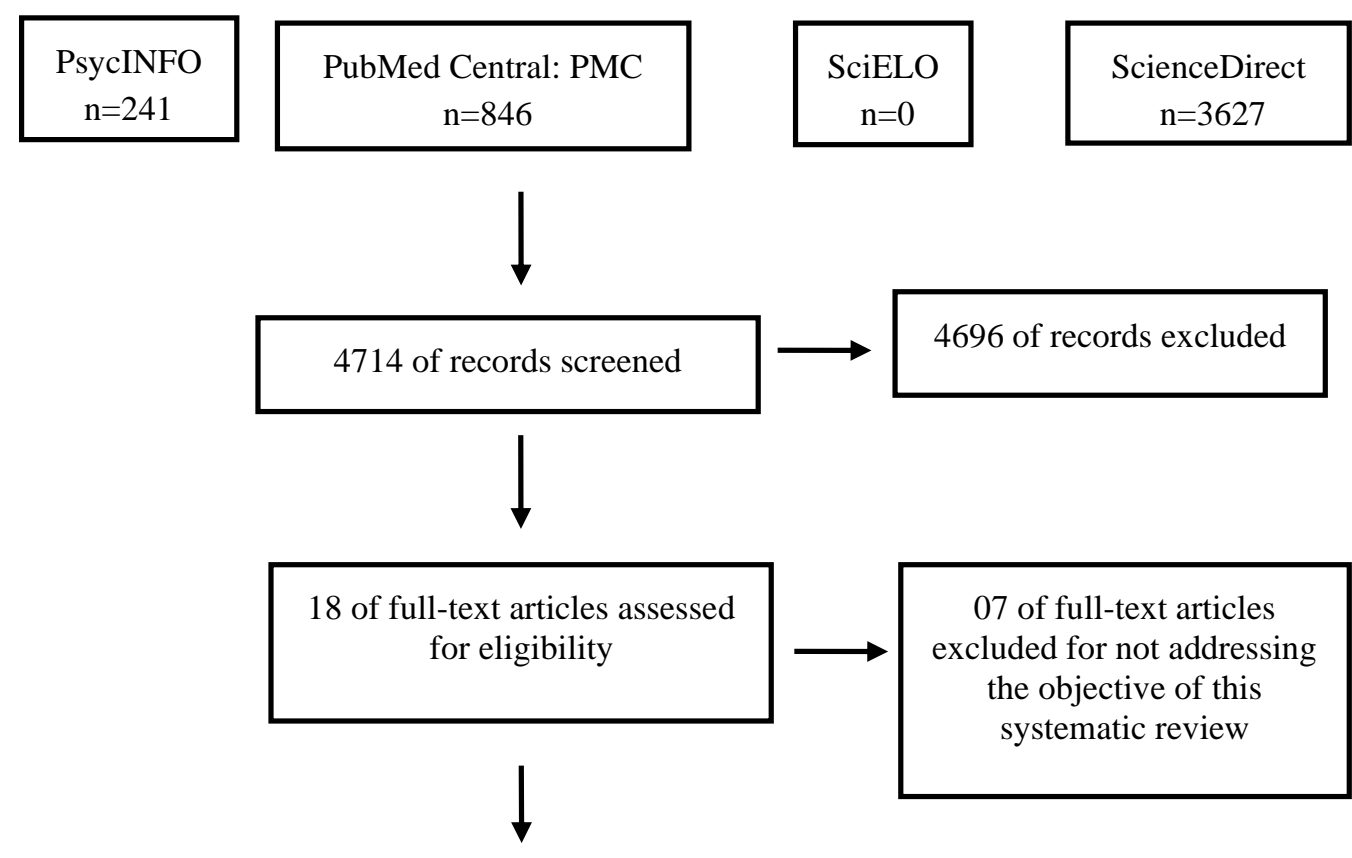

4696 of records excluded

11 of studies included in qualitative synthesis

Source: Authors.

Table 1 displays the following information about the studies in this systematic review: authors, year and country of research, objective, study design, population and characteristics, statistical analysis, and psychological effect identified in the results. 
Table 1. Description of the articles on caregivers' mental health effects of older adult in front of COVID-19 pandemic.

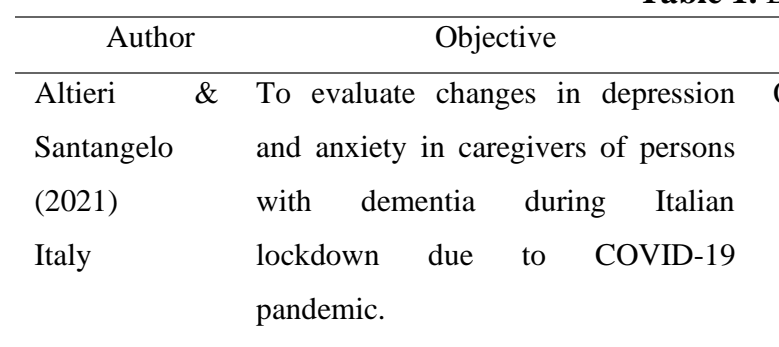

\begin{tabular}{ll}
\hline Archer, & To investigate differences in \\
Reiboldt, & subjective burden before and during \\
Claver, \& Fay & de COVID-19 pandemic among adult \\
(2021) & children who are primary informal \\
USA & caregivers of a parent.
\end{tabular}

Study Design

Population and characteristics

Statistical Analysis

84 caregivers, predominance gender

female $(n=71)$, the sample mean age

was 48.7 years old, mean years of

education were 13.8 years.

Main Results

Quantitative

(3) univariate analysis, $\mathrm{p}$ functional dependence.

Quantitative 77 caregivers , $77.9 \%$ were women, Descriptive statistics, $72.7 \%$ participants answered that they did not have a choice $35.1 \%$ age between $40-49$ years. $\quad t$-test, $\mathrm{p} \leq .0 .05 . \quad$ in becoming the caregiver. pandemic.

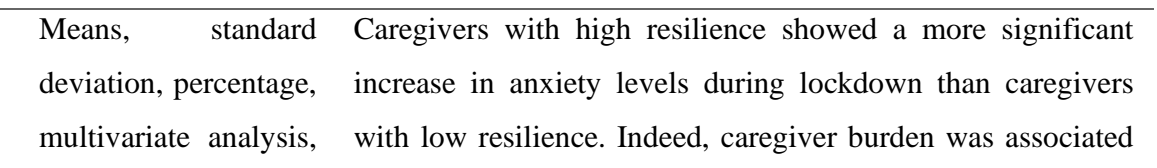

\begin{abstract}
partial eta square, negatively with resilience scores, and positively with higher
\end{abstract}
$<.05$. Psychological interventions need to be provided to reduce levels of depression, anxiety, and caregiver burden.

The burden has increased significantly since the onset of the

Caregiver with siblings experience significantly less burden than those who do not have living siblings. Siblings can be considered a form of social support, highlighting the role of family in offsetting burden in the context of a crisis.

\begin{abstract}
Cohen, Russo, To study how the obligatory social
Campos, \& isolation affected stress caregivers

Allegri (2020) and the burden of care of family

Argentina members of subjects living with dementia in the community after the initial 4 weeks of quarantine in our setting.
\end{abstract}

Quantitative

80 family caregivers, the family was the primary provider

of care in $65 \%$; the average age was 56.21 years (SD 14.07); years of education of family caregivers was 18.46 (SD 6.84); women accounted for $69.23 \%$ of family caregivers. Descriptive and The study did not found a difference in the level of burden inferential analysis, before coronavirus pandemic for family caregivers of persons chi-square tests. $\mathrm{p}<.05$. in the three stages of dementia, but the level of burden of the family caregiver after 4 weeks in quarantine was higher.

The COVID-19 confinement increased stress caregiver independently of the stage of dementia, but those caring for severe dementia had more COVID-19 related stress compared to caregivers assisting with mild dementia.

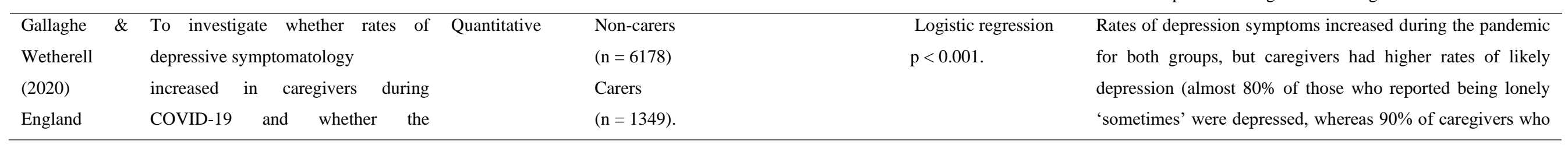


unintended Age - non-carers (47,5 SD 17.70)

consequences of health-protective measures, and see if caregivers

accessed any online/phone psychological support during COVID.
Age - non-carers (47,5 SD 17.70)
carers (52.8 SD 14,79) Gender women

- non-carers $(51,3 \%)$ carers $(61.5)$

COVID-19 lonely often -non-carers

(7.1\%) carers $(8.2 \%)$

Accessed therapy - no: non-carers

$(42,1 \%)$ carers $(59,7 \%)$

COVID-19 depression -yes: non-carers

$(17,9 \%)$ carers $(21,6 \%)$

\begin{tabular}{ll}
\hline Lai et al. & To evaluate \\
(2020) & whether supplementary telehealth via \\
China & video-conferencing platforms \\
& could bring additional benefits to \\
& care-recipient with NCD and their \\
& spousal caregivers at home.
\end{tabular}

spousal caregivers at home.

Quantitative 60 older adults and 60 elderly

caregivers, control group - age: 71.83 (66-82 years), Female $n=18$, Male $\mathrm{n}=12$.

Intervention group - age $72.43(66-82$ years), Female $n=17$, Male $n=13$. Both groups presented caregivers with one or

more chronic diseases.

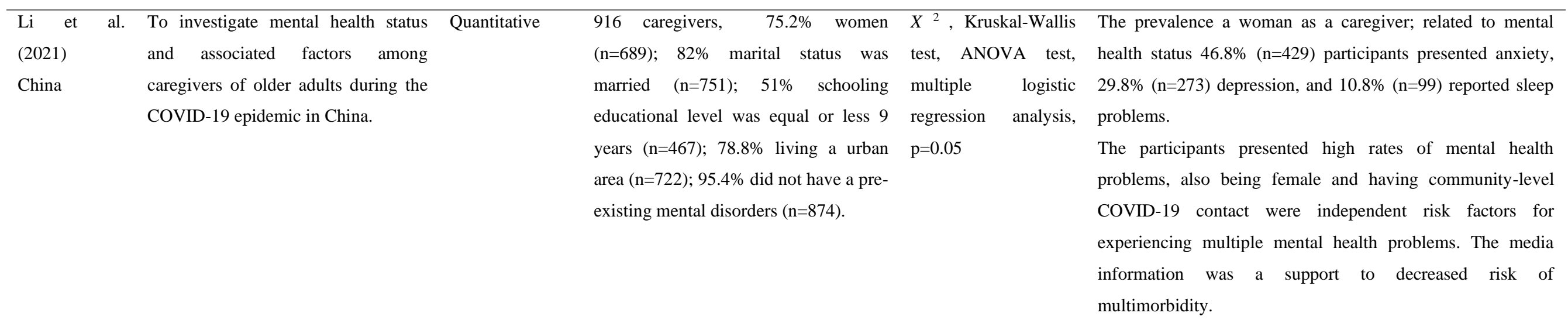

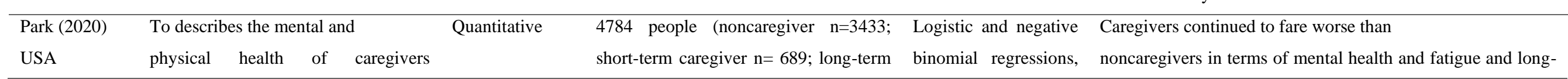
$\mathrm{x}^{2} \quad$ test, and associated with a generally positive impact on the caregivers ANCOVA, $\mathrm{p}<0.05$. (physical and mental status), and positive synergistic interaction between care-recipients and caregivers of a dyad. were not depressed reported never being lonely). Related to access any psychological supports, $60 \%$ of carers with likely depression said they did not access, and $20 \%$ of caregivers with depression symptomatology reported "no need for support". The majority of caregivers do not access any online or phone psychiatric support. 
compared to noncaregivers in

the United States during the early part of the pandemic. caregiver $\mathrm{n}=662)$, gender male $\mathrm{p}$-value not informed.

(noncaregiver 51,4\%; short-term caregiver $40,4 \%$; long-term caregiver $43,9 \%)$ age 50 to 64 years (noncaregiver 27\%; short-term caregiver 30,3\%; long-term caregiver $35,1 \%)$, non-Hispanic white; anxiety and depression prior to pandemic (noncaregiver 21.5\%; short-term caregiver 26,5\%; long-term caregiver $31,6 \%)$.

Rainero et al. To investigate the clinical changes in Quantitative (2021) patients with Alzheimer's disease and Italy other dementias, and evaluate caregivers' distress during COVID-19 quarantine.

\section{3 caregivers, 2934 women, mean} age SD 58.2. 1979 men, mean age SD 60.7 .

$59 \%$ were cohabitants with the patients $36 \%$ were spouses of the dementia care recipient. term caregivers were more likely to report somatic symptoms (headache, body aches, and abdominal discomfort) than both short-term

caregivers and noncaregivers, even after adjusting for demographic, socioeconomic, and preexisting health traits.

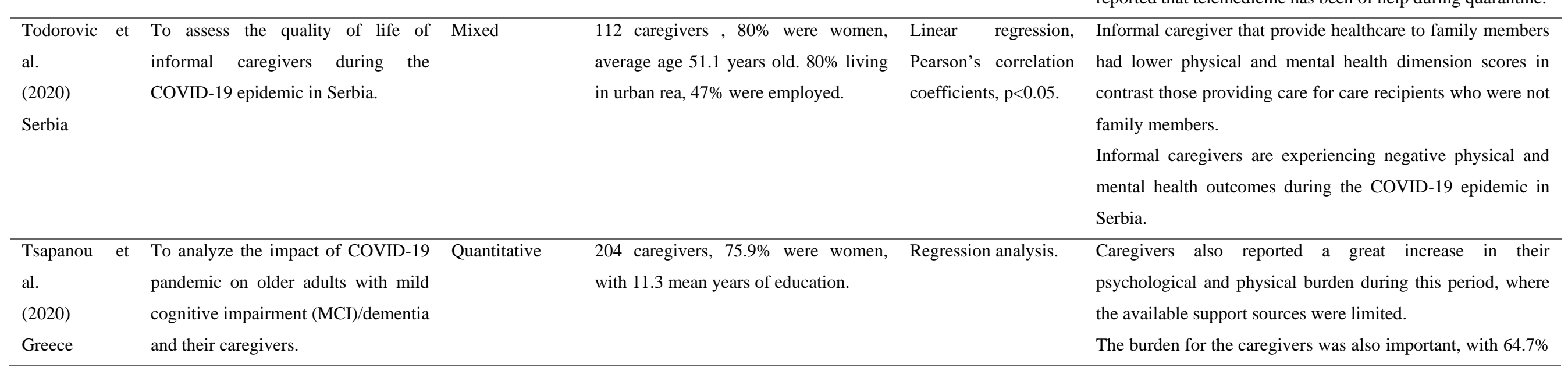




\begin{tabular}{|c|c|c|c|}
\hline $\begin{array}{l}\text { Vaitheswaran } \\
\text { et al. (2020) } \\
\text { India }\end{array}$ & $\begin{array}{l}\text { To describe the experiences and Qualitative } \\
\text { needs of caregivers of persons with } \\
\text { dementia during the COVID-19 } \\
\text { pandemic and lockdown in a city in } \\
\text { India. }\end{array}$ & $\begin{array}{l}31 \text { caregivers, caregivers' mean age Not applied } \\
\text { was } 54.06 \text { years (SD 15.04), women ( } \\
=16) \text {, wife }(n=11) \text {, son }(n=8) \text {, husband } \\
(n=6) \text {, daughter }(n=5) \text {, grandson }(n=1)\end{array}$ & $\begin{array}{l}\text { Caregiver's worries about protecting their relatives with } \\
\text { dementia from SARS CoV-1 infection, and the caregiver's } \\
\text { stigma about COVID-19; caregiver developing health } \\
\text { problems and difficulty to get support for it, and } \\
\text { overwhelming with demands (work and home demands); } \\
\text { some support suggestions: video-consultation (except when } \\
\text { the caregiver doesn't know how to use the technology) and } \\
\text { telephone support. }\end{array}$ \\
\hline
\end{tabular}

Source: Authors.

mentioning a serious increase in their physical burden and $80 \%$ in their phycological burden.

Most of the families did not have a significant support, with only $40.3 \%$ reporting having some support sources available.

The psychological burden of the caregivers was more prominent in the demented group than the two other diagnostic groups.

telephone support. 
Table 1 shows that the study design has predominantly quantitative studies and predominantly international studies, showing a deficit of Brazilian studies and publications related to the theme investigated in this study. The sample characteristics are the caregiver gender being predominantly female, with pre-existing chronic diseases, and some caregivers informed existent symptoms of anxiety and depression before the pandemic.

The caregiver's psychological effects are diverse, like high levels of stress, anxiety, somatic symptoms, and concern on protecting the older adult; also, some studies informed that caregivers of older adult did not access any online or phone psychiatric support because of their lack of technology knowledge, on the other hand, other studies showed that caregivers of older adult, who had received online support demonstrated positive psychological effects.

The literature review on the caregivers' mental health effects of older adult in the COVID-19 pandemic shows that Brazilian literature presents an alarming lack of publications. There is a prevalence of international publications; part of the publications come from Asia and Europe, as both continents had the pandemic first wave, as well as the development of researches and intervention measures for caregivers of older adults.

The studies emphasize psychological effects in the caregiver as somatic symptoms, fatigue and worse mental health status (Park, 2020; Todorovic et al., 2020), anxiety (Li et al., 2021; Rainero et al., 2021) sleep problem (Li et al., 2021), higher levels of stress, and caregiver burden (Archer, Reiboldt, Claver, \& Fay, 2021; Cohen, Russo, Campos, \& Allegri, 2020; Tsapanou et al., 2020), depression symptoms (Altieri \& Santangelo, 2021; Gallaghe \& Wetherell, 2020; Li et al., 2021), change in the lifestyle, reducing time devoted to own activities, increase intrafamilial psychological conflicts (Rainero et al., 2021).

As a mechanism of support for caregivers, the study from Lai et al. (2020) demonstrated that video conference had a positive impact on caregivers, also, it promotes positive synergistic interaction between the older adults and the caregivers; telemedicine (Rainero et al., 2021) and media information was another method to support and decreased risk of multimorbidity (Li et al., 2021); in addition, siblings was considered other form of social support for caregivers in this moment of pandemic (Archer, Reiboldt, Claver, \& Fay, 2021).

Opposite perspective, caregivers refer no access to either online or phone psychiatric support because of the lack of knowledge on technology, or they did not want to use it; however, $60 \%$ of caregivers with depression did not access psychological support, and 20\% of caregivers with depression considered themselves not in need of psychological support (Lai et al., 2020); these findings argue with Migliaccio and Bouzigues' study (2020) that caregivers' physical and psychological health must be supported.

This study aimed to gather empirical evidence on the caregivers' mental health impact of older adult during the COVID-19 pandemic. The principal findings show the negative psychological effects on the caregivers of older adults and the mechanisms used by them in getting support to minimize these psychological impacts during the pandemic moment.

Caregivers are frustrated with the time and effort which they may have lost and worried about (Migliaccio \& Bouzigues, 2020), although the psychological effects in the caregivers are various, like anxiety, sleep problem (Li et al., 2021), stress (Cohen et al., 2020), depression (Altieri \& Santangelo, 2021; Li et al., 2021; Gallaghe \& Wetherell, 2020), irritability (Rainero et al., 2020), worry and stigma about COVID-19 (Vaitheswaran et al., 2020), and somatic symptoms (Park, 2020). Most symptoms are described in the studies from Brooks et al. (2020) and Moraes (2020), the authors outline that these symptoms affect society in general, but have a bigger impact on the vulnerable group, for instance, caregivers of older adults.

The lockdown required for the COVID-19 highly impacted the caregivers (Altieri \& Santangelo, 2021; Pinquart \& Sörensen, 2003), as it generated psychological changes in the caregivers of persons with dementia. For example, levels of depression increased more than anxiety levels, even though negative effects on levels of anxiety during the lockdown were 
evidenced (Altieri \& Santangelo, 2021). Anxiety symptoms could be related to the mandatory isolation due to COVID-19, as people start to feel lonely, bored, or lacking activities (Hwang et al., 2020; Sallim et al., 2015), also, it can be aggravated due to caregiving responsibilities (Fagerström et al., 2020).

In the study from the Ebola epidemic, participants referred to being afraid of death, of transmitting the disease, of being distant from their family and friends, also, of losing friends (Hall, Hall, \& Chapman, 2008). These psychological events promote negative impacts on the caregiver's quality of life, functional dependence, and levels of stress (Savva et al., 2009; Sallim et al., 2015); older caregivers have a high risk of poor quality of life, overwhelming and worsened health evaluation compared to the previous one (Flesch, Batistoni, Neri, \& Cachioni, 2020).

Reflecting on caregivers with comorbidities, as they are in a high-risk group, it is possible to include concerns about themselves becoming ill or losing support and contact with relatives and friends while socially isolated; both factors contribute to experiencing poor sleep quality, disturbed sleep patterns, and high anxiety levels (Killen et al., 2020). In the Taylor et al. (2020) research, it was identified that the presence of preexisting general medical conditions was not associated with heightened total scores on the COVID-19 Stress Scales; however, people with a preexisting mental health disorder had significantly higher total scores the COVID-19 Stress Scales.

As a mental health challenge, caregivers are managing their anxiety and coping with uncertainty (Killen et al., 2020). An example of the mechanism to support and reduce negative effects are the telephone call and video conference to caregivers of older adults (Dhavale, Koparkar, \& Fernandes, 2020; Lai et al., 2020; Rainero et al., 2021) and having siblings (Archer et al., 20201) resulting in a positive impact on the caregivers and positive synergistic interaction between caregivers and the older adult (Lai et al., 2020) and helping caregiver keeping going (Rainero et al., 2021).

As one way to managing their psychological changes, resilience would be one strategy, in the study of Altieri and Santangelo (2021) demonstrated that high levels of resilience in caregivers of people with dementia were associated with lower levels of caregivers burden. In a study developed in Singapore with caregivers of older adults, social support mediates the association between resilience and caregiver burden. This association was mediated by the level of perceived social support (family and friends), thus it can promote and identify family and friend's supportive networks that may help to lessen their burden (Ong et al., 2018).

Another support to account is the psychological support provided for the public health system; the support provided and connection with all families are both contributions to reduce the negative psychological impact on caregivers (Migliaccio \& Bouzigues, 2020). It is essential that caregivers feel well supported to enable them to maintain their caregiving role during the COVID-19 crisis, and health and social care professionals can be sources of both practical and emotional support (Killen et al., 2020).

On the other hand, the difficulty and lack of knowledge about technology made caregivers unable to access online or phone support (Gallaghe \& Wetherell, 2020; Vaitheswaran et al., 2020), this situation is consequences of the lack of access to technology and knowledge in how to use this technology, and difficulty in engaging a person with dementia. Health services need to adopt a pragmatic approach that uses technology when feasible and continues to provide in-person clinical service with safety measures including provision of PPE for all staff and maintaining social-distancing norms (Center for Disease Control and Prevention, 2020).

This difficulty is evidenced in Brazil, a high number of Brazilians do not have an internet connection, this fact limits the opportunities to getting support. Also, people who have internet access, special the older adults, could have difficulty using computers and smartphones emphasizing the difficulty in getting support (Ornell et al., 2020); even in view of this reality and considering the need to offer mental health and general health services to caregivers in the face of the pandemic, the project 
"Coletivos Online" (https://coletivosaudemental.com.br/pesquisa/) is an opportunity to get intervention and support for Brazilians in this moment.

The e-Health solution was developed with Progressive Web App Technology, with the principles of usability and allows access to the various instruments for data collection and scheduling in individual care rooms and groups. To ensure data confidentiality and user privacy, the platform stores the data on a remote server based on secure Web protocols, in order to implement communication between the client and server devices in an encrypted manner. Therefore, it is understood that initiatives of this nature should be encouraged so that Brazil can portray the reality experienced by the population with intervention measures aimed at the health of Brazilians.

Caregivers will take their toll during this pandemic because they are not just caregivers, they become therapists, nurses, rehabilitators, and other professionals who a person in care might need. All these responsibilities provide an immense burden, and caregivers are at risk of forgetting about their own health situation (Migliaccio \& Bouzigues, 2020). Caregivers' physical health must also be supported (Gulia, Mishra, \& Bhatnagar, 2020; Migliaccio \& Bouzigues, 2020). Knowing all the people's reactions to pandemics, it is necessary to promote public health interventions to prevent and minimize the mental health impact on society (Taylor et al., 2020).

Caregivers want help, and they need support like education regarding the patient's care and condition. Caregivers want to feel prepared to know what to expect about caring once caregiving is physically and mentally challenging $\left(\mathrm{O}^{\prime} \mathrm{Connor}\right.$ et al., 2021); also, to know the different expectations of caregivers roles, the feelings of stress due to the expectations placed on them (Guilcher et al., 2021). All of these challenges for the caregiver can be overwhelming, therefore caregivers need to have support. Health professionals must know the importance of providing education to caregivers and make sure they care for themselves, so they could continue in their role as caregivers (Guilcher et al., 2021; O'Connor et al., 2021).

\section{Conclusion}

The findings of this study point to the caregiver's mental health of older adults inequality due to the social isolation and overwhelming demands as a caregiver. It is essential to provide early interventions with or without technologies to minimize the negative effects caused by the COVID-19 pandemic in caregivers. Promoting adequate support to caregivers and the old adult could cause an incidence of caregiver burden and other somatic symptoms.

Finally, some limitations of this study need to be mentioned. The selection of articles restricted to those classified as open access, the restriction to the language of publication of the articles, the period of the research, and the fact that the grey literature and articles describing caregiver's psychological effects related to the other topics were not considered are important variables to be taken into account. In this context, it is observed that many studies sought to investigate issues related to child caregivers, health professionals as a caregivers, and the restriction of caregiver of older adult participation in the research because of the protective restrictions to COVID-19. Given these limitations, the increase of publications focusing on the caregiver's mental psychological effects of older adult should be encouraged, which may lead to a greater understanding of the means of supporting caregivers of older adults and contribute to the development of strategies to prevent and intervene in the negative consequences of the COVID-19 pandemic in mental health.

\section{Acknowledgments}

Higher Education Personnel (CAPES) and Rio Grande do Sul State Research Support Foundation (FAPERGS). 


\section{References}

Albott, C. S., Wozniak, J. R., McGlinch, B. P., Wall, M. H., Gold, B. S., \& Vinogradov, S. (2020). Battle Buddies: Rapid deployment of a psychological resilience intervention for health care workers during the COVID-19 pandemic. International Anesthesia Research Society, 131(1), 43-54. https://doi.org/10.1213/ANE.0000000000004912

*Altieri, M., \& Santangelo, G. (2021). The psychological impact of COVID-19 pandemic and lockdown on caregivers of people with dementia. American Journal of Geriatric Psychiatry, 29(1), 27-34. https://doi.org/10.1016/j.jagp.2020.10.009

APA (American Psychological Association). (2020). Pandemics. https://www.apa.org/practice/programs/dmhi/research-information/pandemics

*Archer, J., Reiboldt, W., Claver, M., \& Fay, J. (2021). Caregiving in quarantine: Evaluating the impact of the COVID-19 pandemic on adult child informal caregivers of a parent. Journal Gerontology \& Geriatric Medicine, 7, 1-7. https://doi.org/10.1177/2333721421990150

Brooks, S. K., Webster, R. K., Smith, L. E., Woodland, L., Wessely, S., Greenbrg, N., \& Rubin, G. J. (2020). The psychological impact of quarantine and how to reduce it: a rapid review of the evidence. The Lancet, 395(10227), 912-920. https://doi.org/10.1016/S0140-6736(20)30460-8

Center for Disease Control and Prevention. (2020). Emergency Consideration for PPE. https:/www.cdc.gov/coronavirus/2019-ncov/hcp/non-ussettings/emergencyconsiderations-ppe.html

*Cohen, G., Russo, M. J., Campos, J. A., \& Allegri, R. F. (2020). Living with dementia: Increased level of caregiver stress in times of COVID-19. International Psychogeriatrics, 1-5. https://doi.org/10.1017/S1041610220001593

Dhavale, P., Koparkar, A., \& Fernandes, P. (2020). Palliative care interventions from a social work perspective and the challenges faced by patients and caregivers during COVID-19. Indian Journal of Palliative Care, 26, S58-62. https://doi.org/10.4103/IJPC.IJPC_149_20

Fagerström, C., Elmstãhl, S., \& Wranker, S. (2020). Analyzing the situation of older family caregivers with a focus on health-related quality of life and pain: A cross-sectional cohort study. Health and Quality of Life Outcomes, 18(79), 1-10. https://doi.org/10.1186/s12955-020-01321-3

Family Caregiver Alliance National Center on Caregiving. Definitions (2014). CareNav. https://www.caregiver.org/pilotIntegratio $\mathrm{n}$ /indexPersistent.html?uri=/definitions- 0 .

Flesch, L. D., Batistoni, S. S. T., Neri, A. L., \& Cachioni, M. (2020). Elderly who care for elderly: Double vulnerability and quality of life. Paidéia, 30 , e3003. https://doi.org/10.1590/1982-4327e3003

*Gallagher, S., \& Wetherell, M. A. (2020). Risk of depression in family caregivers: Unintended consequences of COVID-19. BJPsych Open, 6, e119, 1-5. https://doi.org/10.1192/bjo.2020.99

Gérin, P., \& Zech, E. (2019). Informal caregiver burnout? Development of a theoretical framework to understand the impact of caregiving. Frontiers in Psychology, 10, 1748-1760. https://doi.org/10.3389/fpsyg.2019.01748

Guilcher, S. J. T., Maunula, L., Cadel, L., Everall, A. C., Li, J., \& Kuluski, K. (2021). Caregiving for older adults with hip fractures: Exploring the perspectives of caregivers, providers, and decision-makers in Ontario, Canada. Archives of Gerontology and Geriatrics, 93, 104321. https://doi.org/10.1016/j.archger.2020.104321

Gulia, A., Mishra, S., \& Bhatnagar, S. (2020). Multiple caregiving rose with the novel challenge of COVID-19 pandemic: A crisis situation. Indian Journal of Palliative Care, 26, S163-165. https://doi.org/10.4103/IJPC.IJPC_165_20

Hall, R. C. W., Hall, R., \& Chapman, M. J. (2008). The 1995 Kikwit Ebola outbreak: Lessons hospitals and physicians can apply to future viral epidemics. General Hospital Psychiatry, 30(5), 446-452. https://doi.org/10.1016/j. genhosppsych.2008.05.003

Hwang, E. J., Kim, H., Yoon, S. H., Goo, J. M., \& Park, C. M. (2020). Implementation of a deep learning-based computer-aided detection system for the interpretation of chest radiographs in patients suspected for COVID-19. Korean journal of radiology, 21(10), 1150-1160. https://doi.org/10.3348/kjr.2020.0536

Killen, A., Olsen, K., McKeith, I. G., Thomas, A. J., O’Brien, J. T., Donaghy, P., \& Taylor J. (2020). The challenges of COVID-19 for people with dementia with Lewy bodies and family caregivers. International Journal of Geriatric Psychiatry, 1-6. https://doi.org/10.1002/gps.5393

*Lai, F. H., Yan, E. W., Yu, K. K., Tsui, W., Chan, D. T., \& Yee, B., K. (2020). The protective impact of telemedicine on person with dementia and their caregivers during the COVID-19 pandemic. American Journal of Geriatric Psychiatry, 28(11), 1175-1184. https://doi.org/10.1016/j.jagp.2020.07.019

*Li, Q., Zhang, H., Zhang, M., Li, T., Ma, W., An, C., \& Wang, H. (2021). Mental health multimorbidity among caregivers of older adults during the COVID19 epidemic. The American Journal of Geriatric Psychiatry, 19, S1064-S7481. https://doi.org/10.1016/j.jagp.2021.01.006

Liberati, A., Altman, D. G., Tetzlaff, J., Mulrow, C., Gotzsche, P. C., Ioannidis, J. P. A., \& Moher, D. (2009). The PRISMA statement for reporting systematic reviews and emta-analyses of studies that evaluate health care interventions: Explanation and elaboration. PLoS Medicine, 6(7), e1000100. https://doi.org/10.1371/journal.pmed.1000100

Migliaccio, R., \& Bouzigues, A. (2020). Dementia and COVID-19 lockdown: More than a double blow for patients and caregivers. Journal of Alzheimer's Disease Reports, 4, 231-235. https://doi.org/10.3233/ADR-200193

Moher, D., Liberati, A., Tetzlaff, J., \& Altman, D. G. (2009). Preferred reporting items for systematic reviews and meta-analyses: The PRISMA statement. PLoS Medicine, 6(7), e1000097. https://doi.org/10.1371/journal.pmed.1000097 
Research, Society and Development, v. 10, n. 8, e13210817125, 2021

(CC BY 4.0) | ISSN 2525-3409 | DOI: http://dx.doi.org/10.33448/rsd-v10i8.17125

Moraes, R.F. (2020). Prevenindo conflitos sociais violentos em tempos de pandemia: garantia da renda, manutenção da saúde mental e comunicação efetiva (Nota Técnica 27). Ipea: Diretoria de Estudos e Políticas do Estado, das Instituições e da Democracia. http://repositorio.ipea.gov.br/handle/11058/9836

NASEM (National Academies of Sciences, Engineering, and Medicine). (2020). Rapid expert consultation on SARS-CoV-2 laboratory testing for the COVID19 pandemic. The National Academies Press. https://doi.org/10.17226/25775.

O’Connor, M., Moriarty, H., Schneider, A., Dowdell, E. B., \& Bowles, K. H. (2021). Patients' and caregivers' perspectives in determining discharge readiness from home health. Geriatric Nursing, 42, 151-158. https://doi.org/10.1016/j.gerinurse.2020.12.012

Ong, H. L., Vaingankar, J. A., Abdin, E., Sambasivam, R., Fauziana, R., Tan, M., Chong, S. A., Goveas, R. R., Chiang, P., \& Subramaniam, M. (2018). Resilience and burden in caregivers of older adults: moderating and mediating effects of perceived social support. BMC Psychiatry, 18(27), 1-9. https://doi.org/10.1186/s12888-018-1616-z

Ornell, F., Schuch, J. B., Sordi, A. O., \& Kessler, F. H. P. (2020). "Pandemic fear" and COVID-19: mental health burden and strategies. Brazilian Journal of Psychiatry. https://doi.org/10.1590/1516-4446-2020-0008

*Park, S. S. (2020). Caregivers' mental health and somatic symptoms during COVID-19. Journals of Gerontology Social Sciences, 1-6. https://doi.org/10.1093/geronb/gbaa121

Pinquart, M., \& Sörensen, S. (2003). Differences between caregivers and noncaregivers in psychological health and physical health: a metaanalysis Psychology and Aging, 18(2), 250-267. https://doi.org/10.1037/0882-7974.18.2.250

*Rainero, I., Bruni, A., Marra, C., Cagnin, A., Bonanni, L., Cupidi, C., \& the SINdem COVID-19 Study Group. (2021). The impact of COVID-19 quarantine on patients with dementia and family caregivers: A nation-wide survey. Frontiers in Aging neuroscience, 12, 625-781. https://doi.org/10.3389/fnagi.2020.625781

Sallim, A. B., Sayampanathan, A. A., Cuttilan, A., \& Ho, R. C. (2015). Prevalence of mental health disorders among caregivers of patients with Alzheimer's disease. The Journal of Post-Acute and Long-Term Care Medicine, 16(12), 1034-1041. https://doi.org/10.1016/j.amda.2015.09.007

Savva, G., Zaccai, J., Matthews, F., Davidson, J., Mckeith, I., \& Brayne, C. (2009). Prevalence correlates course of behavioural and psychological symptoms of dementia in the population. British Journal of Psychiatry, 194(3), 212-219. https://doi.org/10.1192/bjp.bp.108.049619

Taylor, S., Landry, C. A., Paluszek, M. M., Fergus, T., McKay, D., \& Asmundson, G. J. G. (2020). COVID stress syndrome: Concept, structure, and correlates. Anxiety and Depression Association of American, 37, 706-714. https://doi.org/10.1002/da.23071

*Todorovic, N., Vracevic, M., Rajovic, N., Pavlovic, V., Madzarevic, P., Cumic, J., \& Millic, N. (2020). Quality of life of informal caregivers behind the scene of the COVID-19 epidemic in Serbia. MDPI Jounal Medicina, 56, 647-657. https://doi.org/10.3390/medicina56120647

*Tsapanou, A., Papatriantafyllou, J. D., Yiannopoulou, K., Sali, D., Kalligerou, F., Ntanasi, E., \& Sakka, P. (2020). The impacto f COVID-19 pandemic on people with mild cognitive impairment/dementia and on their caregivers. International Journal Geriatric Psychiatry, 36, 583-587. https://doi.org/10.1002/gps.5457

*Vaitheswaran, S., Lakshminarayanan, M., Ramanujam, V., Sargunan, S., \& Venkatesan, S. (2020). Experiences and needs of caregivers of persons with dementia in India during the COVID-19 pandemic: A qualitative study. American Journal of Geriatric Psychiatry, 28(11), 1185-1194. https://doi.org/10.1016/j.jagp.2020.06.026

World Health Organization. (2020). Mental health and psychosocial considerations during the COVID-19 outbreak. https://www.who.int/publicationsdetail/mental-health-and-psychosocial-considerations-during-the-covid-19-outbreak

World Health Organization. (2017). Rapid reviews to strengthen health policy and systems: A practical guide. Retrieved from https://www.who.int/alliancehpsr/resources/publications/rapid-review-guide/en/ 